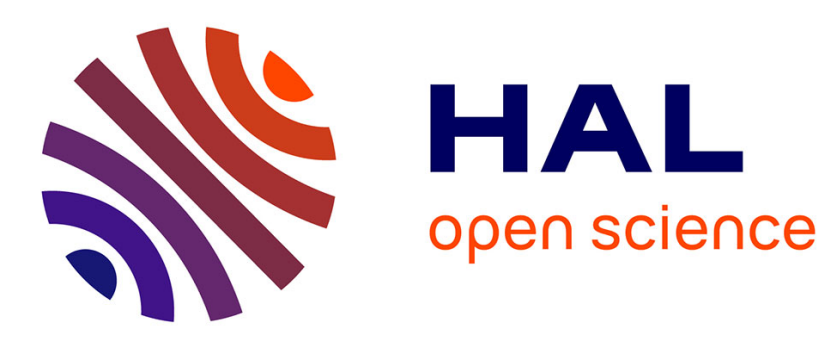

\title{
A Two-Electron Silver Superatom Isolated from Thermally Induced Internal Redox Reactions of A Silver(I) Hydride
}

Yu-Jie Zhong, Jian-Hong Liao, Tzu-Hao Chiu, Samia Kahlal, Che-Jen Lin, Jean-Yves Saillard, Chen-Wei Liu

\section{To cite this version:}

Yu-Jie Zhong, Jian-Hong Liao, Tzu-Hao Chiu, Samia Kahlal, Che-Jen Lin, et al.. A Two-Electron Silver Superatom Isolated from Thermally Induced Internal Redox Reactions of A Silver(I) Hydride. Angewandte Chemie International Edition, 2021, 60 (23), pp.12712-12716. 10.1002/anie.202100965 . hal-03193315

\section{HAL Id: hal-03193315 https://hal.science/hal-03193315}

Submitted on 16 Jun 2021

HAL is a multi-disciplinary open access archive for the deposit and dissemination of scientific research documents, whether they are published or not. The documents may come from teaching and research institutions in France or abroad, or from public or private research centers.
L'archive ouverte pluridisciplinaire HAL, est destinée au dépôt et à la diffusion de documents scientifiques de niveau recherche, publiés ou non, émanant des établissements d'enseignement et de recherche français ou étrangers, des laboratoires publics ou privés. 
WILEY-VCH

\title{
A Two-Electron Silver Superatom Isolated from Thermally Induced Internal Redox Reaction of A Silver(I) Hydride
}

\author{
Yu-Jie Zhong, ${ }^{[a]}$ Jian-Hong Liao, ${ }^{[a]}$ Tzu-Hao Chiu, ${ }^{[a]}$ Samia Kahlal, ${ }^{[b]}$ Che-Jen Lin, ${ }^{[a]}$ Jean-Yves \\ Saillard ${ }^{*[b]}$ and C. W. Liu*[a]
}
[a] Y.-J. Zhong, Dr. J.-H. Liao, T.-H. Chiu, Prof. Dr. Che-Jen Lin, Prof. Dr. C. W. Liu
Department of Chemistry
National Dong Hua University
No. 1, Sec. 2, Da Hsueh Rd., Hualien 974301, Taiwan (R.O.C.)
E-mail: chenwei@mail.ndhu.edu.tw
Homepage: http://faculty.ndhu.edu.tw/ cwl/index.htm
[b] Dr. S. Kahlal, Prof. Dr. J.-Y. Saillard
Univ Rennes, CNRS, ISCR-UMR 6226
F-35000 Rennes, France
E-mail: jean-yves.saillard@univ-rennes1.fr

Supporting information (experimental and computational details) of this article can be found under https://doi.org/10.1002/anie.xxxxxxxxx.

\begin{abstract}
Rational syntheses under controllable reducing conditions in the preparation of superatoms with cluster electron not exceeding two are challenging. Herein a dithiolate-stabilized two-electron silver nanocluster, $\mathrm{Ag}_{10}\left\{\mathrm{~S}_{2} \mathrm{P}\left(\mathrm{O}^{\prime} \mathrm{Pr}\right)_{2}\right\}_{8}(\mathbf{1})$, is isolated via a self-redox reaction of $\mathrm{Ag}_{7}(\mathrm{H})\left\{\mathrm{S}_{2} \mathrm{P}\left(\mathrm{O}^{\prime} \mathrm{Pr}\right)_{2}\right\}_{6}$ without adding extra reducing agents. The metal framework of $\mathrm{Ag}_{7}$, a bicapped trigonal bipyramid, is highly correlated to that of $\mathrm{Ag}_{10}$, suggesting $\mathrm{Ag}_{7}(\mathrm{H})\left\{\mathrm{S}_{2} \mathrm{P}\left(\mathrm{O}^{\prime} \mathrm{Pr}\right)_{2}\right\}_{6}$ acts as both reducing agent and template in cluster growth. 1 is highly fluorescent at ambient temperature and TD-DFT calculations indicate that the emission is of $1 P_{x} \rightarrow 1 S$ nature.
\end{abstract}

The chemistry of atomically and structurally precise nanoclusters (NCs) has undergone a renaissance over the past few years owing to their numerous properties. ${ }^{[1]}$ The stability and structure of NCs can often be rationalized within the concept of superatom and its "magic" closed-shell electron counts of 2, 8, 18, 20, 34, 40, 58... ${ }^{[2]}$ Whereas the majority of reported silver superatoms are 8electron species, ${ }^{[3]}$ examples of 2-electron superatoms are surprisingly fewer (Table S1). ${ }^{[4-10]}$ The first one, $\mathrm{Ag}_{14}\left(\mathrm{SC}_{6} \mathrm{H}_{3} \mathrm{~F}_{2}\right)_{12}\left(\mathrm{PPh}_{3}\right)_{8}$, was published in $2013^{[4]}$ It was followed in the same year by $\left[\mathrm{Ag}_{6}\left(\mathrm{Y}-\mathrm{H}_{2} \mathrm{SiW}_{10} \mathrm{O}_{36}\right)_{2}\right]^{8-,[5]}$ and $\mathrm{Ag}_{16}(\mathrm{dppe})_{4}\left(\mathrm{SC}_{6} \mathrm{H}_{3} \mathrm{~F}_{2}\right)_{14 .}{ }^{[6]}$ Additional 2-electron $\mathrm{Ag} \mathrm{NCs}$ were reported only recently, thus becoming a hot topic in the NC community. ${ }^{[7-10]}$ Most of the 2-electron Ag NCs listed in Table S1 have an octahedral $\left[\mathrm{Ag}_{6}\right]^{4+}$ superatomic core, and the other silver atoms of the cluster, if any, are formally $\mathrm{Ag}(\mathrm{I}) .^{[4-5,7]}$ The tetracapped tetrahedral $\left[\mathrm{Ag}_{8}\right]^{6+}$ core is also well represented. ${ }^{[7 \mathrm{e}]}$ Other examples display rhombohedral $\left[\mathrm{Ag}_{8}\right]^{6+},{ }^{60]}$ fcc-packed $\left[\mathrm{Ag}_{7}\right]^{5+},{ }^{[8]}$ or anti-cuboctahedral $\left[\mathrm{Ag}_{13}\right]^{11+}{ }^{[9]}$ cores. Most of them are co-protected by two or more types of ligands such as phosphines, thiolates, alkynyls, or polyoxometalates. ${ }^{[4-9]}$ So far, only one homoleptic two-electron $\mathrm{NC},\left[\mathrm{Ag}_{8}(\mathrm{pfga})_{6}\right]^{6-}$, is known. ${ }^{[10]}$ In the present contribution, we report the isolation of a homoleptic, dithiolate-stabilized $\mathrm{Ag}_{10}$ 2-electron $\mathrm{NC}$ whose metal core is totally different from the above mentioned structures. Whereas most of the above-mentioned 2-electron species were prepared with borohydride, ${ }^{[4,6,9]}$ silane, ${ }^{[5]}$ or $\mathrm{DMF}^{[7,10]}$ as reducing agents (Table S1), controlling the amount of reductants used in their synthesis to avoid the formation of 8-electron species can be problematic. Herein we describe an unprecedented controllable synthesis of a new 2-electron NC without additions of any reducing agent, that is, starting from a pre-organized silver(I) hydride compound as a both reducing agent and template. To the best of our knowledge, it is the first example of a thermally induced internal redox reaction of silver(I) hydride leading to the formation of a superatomic NC.

We have observed that the $\mathrm{Ag}_{7}(\mathrm{H})\left\{\mathrm{S}_{2} \mathrm{P}\left(\mathrm{O}^{\prime} \mathrm{Pr}\right)_{2}\right\}_{6}{ }^{[11]}$ solution gradually changes color from transparent to light purple at ambient temperature, and then exhibits red emission under UV irradiation. However, this color change takes a long time. To speed up the process, the temperature was elevated to $60^{\circ} \mathrm{C}$. The experiment was carried out in a sealed NMR tube containing only $\mathrm{Ag}_{7}(\mathrm{H})\left\{\mathrm{S}_{2} \mathrm{P}\left(\mathrm{O}^{\prime} \mathrm{Pr}\right)_{2}\right\}_{6}$ and $\mathrm{CDCl}_{3}$. Time-dependent ${ }^{31} \mathrm{P}\left\{{ }^{1} \mathrm{H}\right\}$ (Figure 1a) and ${ }^{1} \mathrm{H}$ (Figure 1b) NMR spectra were acquired from 0 to 72 hours. Almost no change occurred during the first three hours and a pseudo octet of octets coupling of hydride and silver nuclei was clearly seen in the ${ }^{1} \mathrm{H}$ NMR spectrum. After six hours, a peak centered at $104.5 \mathrm{ppm}$ appeared in the ${ }^{31} \mathrm{P}\left\{{ }^{1} \mathrm{H}\right\}$ NMR spectrum, assignable to a new compound $\mathbf{1}$, identified later as $\mathrm{Ag}_{10}\left\{\mathrm{~S}_{2} \mathrm{P}\left(\mathrm{O}^{\prime} \mathrm{Pr}\right)_{2}\right\}_{8}$ (vide infra) and in-situ generated $\mathrm{H}_{2}$ gas was identified at $4.6 \mathrm{ppm}$ in the ${ }^{1} \mathrm{H}$ NMR spectrum. As the reaction continues, the intensities of the peak at $104.5 \mathrm{ppm}$ and that of a new broad peak at $106.5 \mathrm{ppm}$ increase. After 72 hours, the hydride resonance had completely disappeared, indicating that the $\mathrm{Ag}_{7}(\mathrm{H})\left\{\mathrm{S}_{2} \mathrm{P}\left(\mathrm{O}^{\prime} \mathrm{Pr}\right)_{2}\right\}_{6}$ reactant was completely consumed. The residual products are $\mathbf{1}$ and the species resonating at $106.5 \mathrm{ppm}$

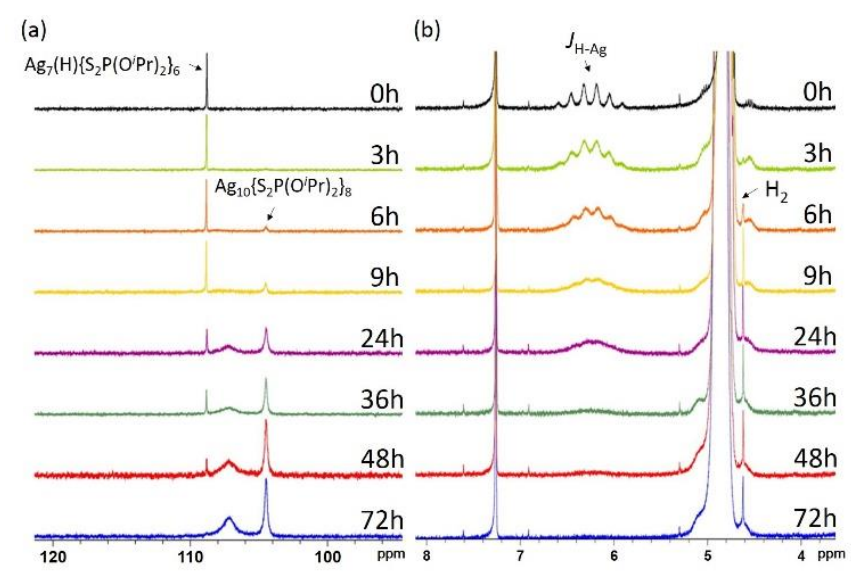

Figure 1. (a) Time-dependent ${ }^{31} \mathrm{P}\left\{{ }^{1} \mathrm{H}\right\}$ and (b) ${ }^{1} \mathrm{H}$ NMR spectra of $\mathbf{1}$, recorded in a sealed NMR tube. 
(a)

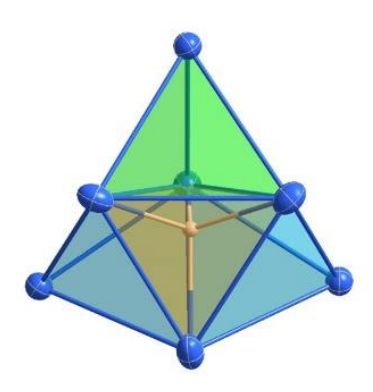

(b)

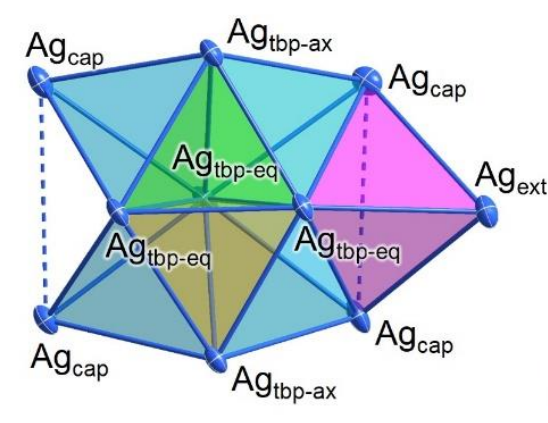

(c)

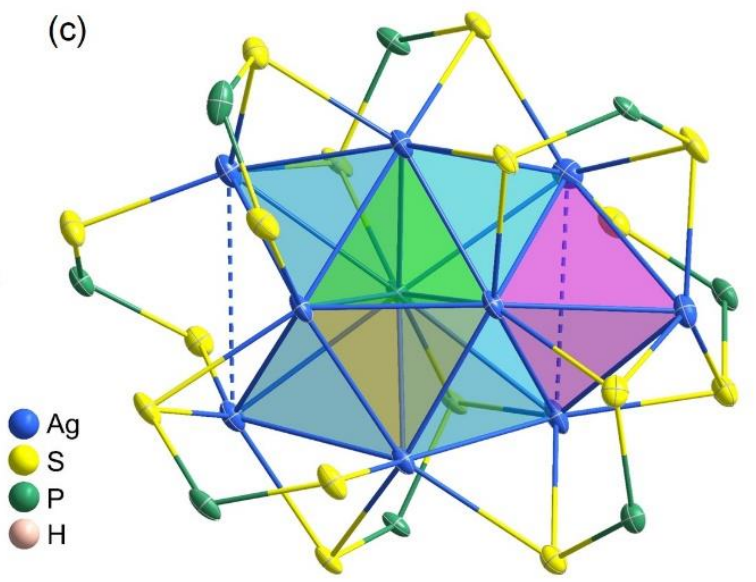

Figure 2. (a) A schematic representation of $\mathrm{Ag}_{7}(\mathrm{H})$ core, and (b) $\mathrm{Ag}_{10}$ core in 1. (c) The total structure of $\left[\mathrm{Ag}_{10}\left\{\mathrm{~S}_{2} \mathrm{P}\left(\mathrm{O} \mathrm{Pr}_{2}\right\}_{8}\right]\right.$ with isopropoxy groups omitted for clarity.

in the ${ }^{31} \mathrm{P}$ NMR spectrum, which was identified as the $\left[\mathrm{Ag}\left\{\mathrm{S}_{2} \mathrm{P}\left(\mathrm{O}^{\prime} \mathrm{Pr}\right)_{2}\right\}\right]_{n}$ polymer (see below). The balanced reaction equation (Scheme 1) describes a self-redox process. We suggest that the encapsulated hydride of $\mathrm{Ag}_{7}(\mathrm{H})\left\{\mathrm{S}_{2} \mathrm{P}\left(\mathrm{O}^{\prime} \mathrm{Pr}\right)_{2}\right\}_{6}$ partly reduces the cluster silver $(\mathrm{I})$ atoms, eventually yielding the 2electron superatom $\mathbf{1}$, concomitantly with the hydride oxidation in $\mathrm{H}_{2}$.

$2\left[\mathrm{Ag}_{7}(\mathrm{H})\left\{\mathrm{S}_{2} \mathrm{P}\left(\mathrm{O}^{i} \mathrm{Pr}\right)_{2}\right\}_{6}\right] \underset{\mathrm{THF}}{\stackrel{60^{\circ} \mathrm{C}}{\longrightarrow}}\left[\mathrm{Ag}_{10}\left\{\mathrm{~S}_{2} \mathrm{P}\left(\mathrm{O}^{i} \mathrm{Pr}\right)_{2}\right\}_{8}\right]+4 / \mathrm{n}\left[\mathrm{Ag}\left\{\mathrm{S}_{2} \mathrm{P}\left(\mathrm{O}^{i} \mathrm{Pr}\right)_{2}\right\}\right]_{\mathrm{n}}+\mathrm{H}_{2}$

Scheme 1. The internal redox reaction of $\mathrm{Ag}_{7}(\mathrm{H})\left\{\mathrm{S}_{2} \mathrm{P}\left(\mathrm{O}^{\prime} \mathrm{Pr}\right)_{2}\right\}_{6}$.

Unfortunately, the slow transformation process at high temperature also favors decomposition. As a result, the highest yields possible reach $\sim 42 \%$. An alternative reaction was performed by adding 0.5 equivalent of $\left[\mathrm{Ag}\left\{\mathrm{S}_{2} \mathrm{P}\left(\mathrm{O}^{\prime} \mathrm{Pr}\right)_{2}\right\}\right]_{6}{ }^{[12]}$ to an $\mathrm{Ag}_{7}(\mathrm{H})\left\{\mathrm{S}_{2} \mathrm{P}\left(\mathrm{O}^{\prime} \mathrm{Pr}\right)_{2}\right\}_{6}$ solution, then kept stirring at $60^{\circ} \mathrm{C}$ (Figure $\mathrm{S} 1$, Scheme S2). Compound 1 can be formed in larger quantities within three hours, compared to the self-redox reaction of Scheme 1. $\mathrm{H}_{2}$ is clearly detected in the ${ }^{1} \mathrm{H}$ NMR spectrum (Figure S2). As a result, the yield of 1 increases to $~ 53 \%$ after 24 hours, but starts to decrease for longer periods due to thermal instability of 1 . It can be assumed that when the self-redox reaction of $\mathrm{Ag}_{7}(\mathrm{H})\left\{\mathrm{S}_{2} \mathrm{P}\left(\mathrm{O}^{\prime} \mathrm{Pr}\right)_{2}\right\}_{6}$ occurs, the presence of $\left[\mathrm{Ag}\left\{\mathrm{S}_{2} \mathrm{P}\left(\mathrm{O}^{\prime} \mathrm{Pr}\right)_{2}\right\}\right]_{6}$ (Scheme S2) provides the building materials to speed up the formation of 1. Nevertheless, the thermally induced internal redox reaction of $\mathrm{Ag}_{7}(\mathrm{H})\left\{\mathrm{S}_{2} \mathrm{P}\left(\mathrm{O}^{\prime} \mathrm{Pr}\right)_{2}\right\}_{6}$ discussed here is reminiscent of the degradation of the $\mathrm{Cu}(\mathrm{I})$ hydride $\left[\mathrm{Cu}_{15}(\mathrm{H})_{2}(\mathrm{dtc})_{6}\left(\mathrm{C}_{2} \mathrm{Ph}\right)_{6}\right]^{+}(\mathrm{dtc}$ $=$ dithiocarbamate) into the 2-electon superatom $\left[\mathrm{Cu}_{13}(\mathrm{dtc})_{6}\left(\mathrm{C}_{2} \mathrm{Ph}\right)_{4}\right]^{+}$. The latter was proposed to be generated from the former via sequential loss of $\left[\mathrm{CuC}_{2} \mathrm{Ph}\right]$ and $\mathrm{H}_{2}$ formation. ${ }^{13]}$

Interestingly, the X-ray structure of $\mathbf{1}^{[14]}$ exhibits a metal framework that is closely related to that of its precursor $\mathrm{Ag}_{7}(\mathrm{H})\left\{\mathrm{S}_{2} \mathrm{P}(\mathrm{OEt})_{2}\right\}_{6} \cdot{ }^{[11]} \mathrm{The} \mathrm{Ag}_{7}(\mathrm{H})$ core of the latter can be viewed as a bicapped trigonal bipyramid (Figure 2a) with an encapsulated hydride lying in the yellow tetrahedron. The $\mathrm{Ag}_{10}$ metal framework in 1 (Figure 2b) contains the bicapped trigonal bipyramid of $\mathrm{Ag}_{7}$ core, and additionally possesses two supplementary Ag atoms $\left(A g_{\text {cap }}\right)$ that cap the bipyramid. The resulting tetracapped trigonal bipyramid is further capped by an outer atom $\left(\mathrm{Ag}_{\mathrm{ext}}\right)$, which connects two $\mathrm{Ag}_{\text {cap }}$ and one of the bipyramid equatorial atoms
$\left(A g_{\text {tbp-eq }}\right)$, as illustrated in Figure $2 \mathrm{~b}$. In the structure of $\mathbf{1}$ (Table $\mathrm{S} 2)$, the edge distances of the yellow tetrahedron (2.7985(13)2.9567(13) $\AA$, avg. 2.8562(13) $\AA$ ) are similar to those in green tetrahedron (2.7848(14)-2.9192(13) $\AA$, avg. 2.8553(13) $\AA$ ). This is not the case for $\mathrm{Ag}_{7}(\mathrm{H})\left\{\mathrm{S}_{2} \mathrm{P}(\mathrm{OEt})_{2}\right\}_{6}$ in which the edges of the hydride-containing yellow tetrahedron (3.149(3)-3.161(3) A, avg. $3.155(3) \AA$ ) are significantly larger than those in the green tetrahedron (2.939(3)-3.161(3) $\AA$, avg. 3.050(3) $\AA$ ). ${ }^{[11]}$ Thus, the equivalency between the yellow and green tetrahedra in $\mathbf{1}$ is consistent with the absence of hydride encapsulation. The four cyan tetrahedra in 1 are similar, with average edges (2.9495(13) $\AA$ ) slightly larger than those of the bipyramid. The magenta tetrahedron is the largest, with average edges of 3.150(1) $\AA$. Overall, both $\mathrm{Ag}_{7}(\mathrm{H})\left\{\mathrm{S}_{2} \mathrm{P}(\mathrm{OEt})_{2}\right\}_{6}$ and $\mathbf{1}$ contain a similar bicapped trigonal bipyramidal metal core, strongly suggesting that the former behaves as a template to generate the latter.

The $\mathrm{Ag}_{10}$ framework of $\mathbf{1}$ is surrounded by eight dithiophosphate ligands (Figure 2c) in three coordination modes: one in bimetallic biconnectivity $\left(\mu_{2}:\left(\eta^{1}, \eta^{1}\right)\right)$, three in trimetallic triconnectivity $\left(\mu_{3}\right.$ : $\left.\left(\eta^{1}, \eta^{2}\right)\right)$, and four in tetrametallic tetraconnectivity $\left(\mu_{4}:\left(\eta^{2}, \eta^{2}\right)\right) .{ }^{[15]}$ Discarding the $\mathrm{Ag}-\mathrm{Ag}$ contacts, all the $\mathrm{Ag}$ atoms are tricoordinated $\left(\mathrm{AgS}_{3}\right)$, but the three $\mathrm{Ag}_{\text {tbp-eq. }}$ which are bi-coordinated $\left(\mathrm{AgS}_{2}\right)$. The room-temperature ${ }^{31} \mathrm{P}\left\{{ }^{1} \mathrm{H}\right\}$ NMR spectrum reveals eight ligands in two environments (105.4 and $104.5 \mathrm{ppm}$ ) with the integration ratio of $\sim 1: 7$ (Figure S3). The 293K-213K VT ${ }^{31} \mathrm{P}\left\{{ }^{1} \mathrm{H}\right\}$ NMR spectra (Figure S5) display slightly broadened peaks at $213 \mathrm{~K}$, indicating that all coordination environments are not discernible due to fluxional behavior in solution, even at low temperature. Presumably, the small peak at $105.4 \mathrm{ppm}$ can be inferred to the unique ligand in bimetallic $\left(\eta^{1}, \eta^{1}\right)$ connectivity.

The positive-mode ESI mass spectrum of $\mathbf{1}$ (Figure 3a) shows a molecular ion peak at $\mathrm{m} / \mathrm{z} 2892.0670$ corresponding to the intact neutral cluster with an additional silver ion, $\left[1+\mathrm{Ag}^{+}\right]^{+}$(calc. $\mathrm{m} / \mathrm{z}$ 2892.0923). The compound resonating at $106.5 \mathrm{ppm}$ in the ${ }^{31} \mathrm{P}$ NMR spectrum was separated by chromatography and its positive-mode ESI mass spectrum displayed an enveloped distribution corresponding to $\left[\mathrm{Ag}_{n}\left\{\mathrm{~S}_{2} \mathrm{P}\left(\mathrm{O}^{\prime} \mathrm{Pr}\right)_{2}\right\}_{n}+\mathrm{Ag}^{+}\right]^{+}, \mathrm{n}=3-10$ (Figure S6, Table S3), indicative of a $\left[\mathrm{Ag}\left\{\mathrm{S}_{2} \mathrm{P}\left(\mathrm{O}^{\prime} \mathrm{Pr}\right)_{2}\right\}\right]_{n}$ polymer.

The UV-vis absorption spectrum (Figure $3 b$ ) of 1 in 2-MeTHF shows two prominent bands at $348 \mathrm{~nm}\left(\varepsilon=15500 \mathrm{M}^{-1} \mathrm{~cm}^{-1}\right), 392$ $\mathrm{nm}\left(\varepsilon=21300 \mathrm{M}^{-1} \mathrm{~cm}^{-1}\right)$, and a characteristic peak at $520 \mathrm{~nm}(\varepsilon=$ $\left.8100 \mathrm{M}^{-1} \mathrm{~cm}^{-1}\right)$. Compound 1 shows red emission under UV irradiation at ambient temperature, in both solid state $(725 \mathrm{~nm})$ 
(a)
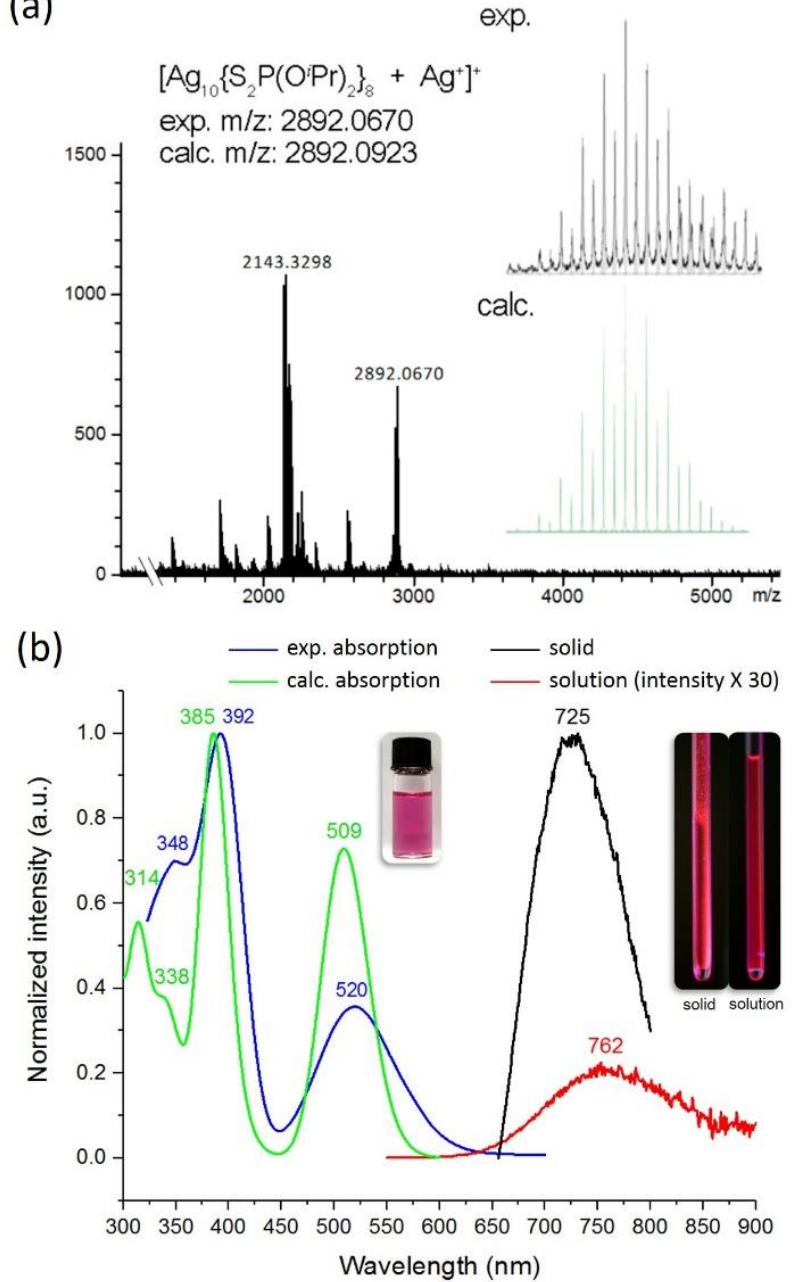

Figure 3. (a) The positive-mode ESI mass spectrum of 1, the inset spectra are experimental (top) and calculated (bottom) isotopic distribution pattern of $\left[\mathrm{Ag}_{10}\left\{\mathrm{~S}_{2} \mathrm{P}\left(\mathrm{O}^{\prime} \mathrm{Pr}\right)_{2}\right\}_{8}+\mathrm{Ag}^{+}\right]^{+}$. (b) Experimental (blue), calculated (green) absorption, and emission spectra of $\mathbf{1}$ in solid (black) and 2-MeTHF (red) at ambient temperature. The intensity of $\mathbf{1}$ in 2-MeTHF is increased by 30 times for comparison. The inset pictures are the compound 1 (left) in 2-MeTHF, and 1 in solid and 2-MeTHF irradiated under UV light (right).

and solution (762 nm), and the emission intensity in solid state is $\sim 150$ times stronger than that in solution ( $Q Y=6.0 \%$ ). A pronounced emission blue-shift occurs at 77K (Figure S7) in both solid $(693 \mathrm{~nm})$ and 2-MeTHF glass $(687 \mathrm{~nm})$. In contrast to $\mathbf{1}$, $\left[\mathrm{Ag}_{7}(\mathrm{H})\left\{\mathrm{S}_{2} \mathrm{P}\left(\mathrm{O}^{\prime} \mathrm{Pr}\right)_{2}\right\}_{6}\right.$ shows very weak yellow emission at $77 \mathrm{~K}$. The stability of $\mathbf{1}$ can be determined by time-dependent UV-vis absorption spectra. The absorption profiles do not change in dark over 14 days (Figure S8a), but gradually decreases under day light in 6 days (Figure S8b). The photoluminescence (PL) lifetime of $\mathbf{1}$ in 2-MeTHF recorded at room temperature (Figure S9) is 2.0 ns $(96.5 \%)$ and $7.3 \mathrm{~ns}(3.5 \%)$, which differs significantly from the lifetime (0.4 ns, $47.3 \% ; 7.0 \mathrm{~ns}, 52.7 \%)$ in solid state at RT (Figure $\mathrm{S} 11)$. It demonstrated longer lifetime in both frozen glass $(0.1 \mathrm{~ns}$, $9.4 \% ; 15.4 \mathrm{~ns}, 90.6 \%$ ) and solid (0.6 ns, $7.6 \% ; 12.9 \mathrm{~ns}, 92.6 \%$ ) at $77 \mathrm{~K}$. This can be attributed to the hampering of molecular motion in the condensed phases, which reduces non-radioactive decay. In any event, the recorded lifetimes are consistent with a fluorescence behavior. Photophysical data of $\mathbf{1}$ are summarized in Table S4.

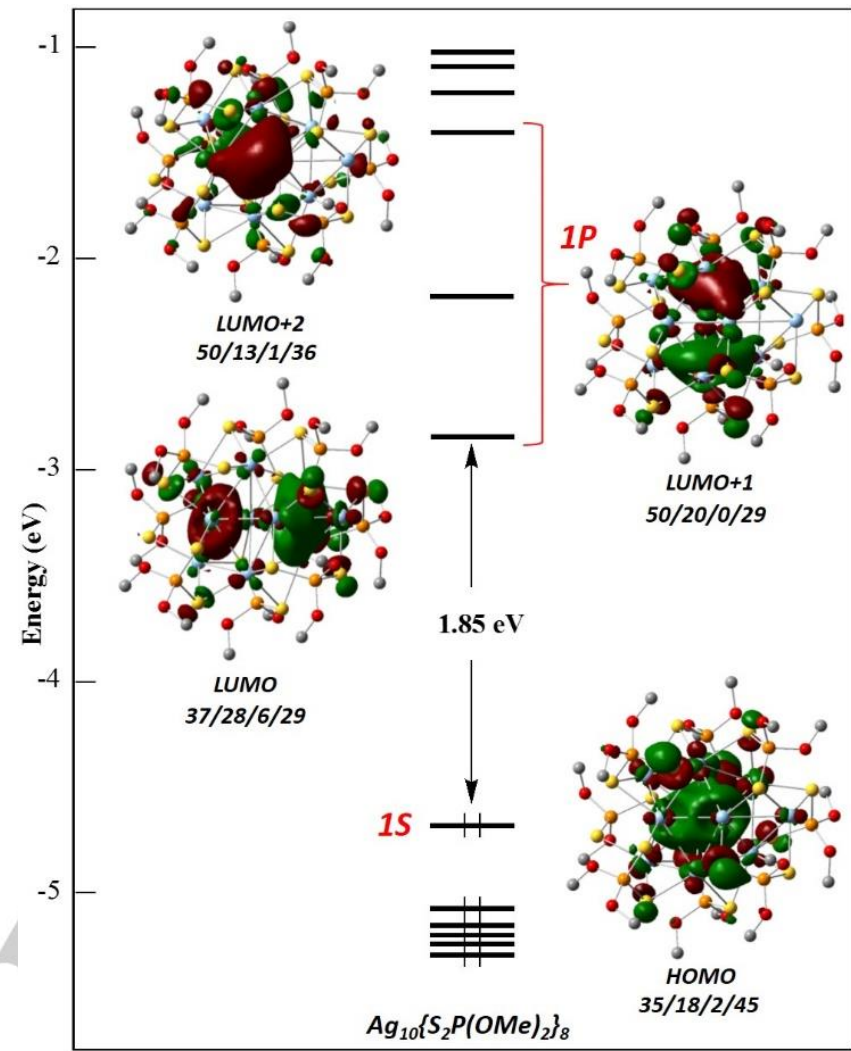

Figure 4. Kohn-Sham orbital diagram of 1'. The MO localizations (in \%) are given in the following order: $\left(\mathrm{Ag}_{\mathrm{tbp}}\right)_{5} /\left(\mathrm{Ag}_{\mathrm{cap}}\right)_{4} / \mathrm{Ag}_{\mathrm{ext}} /$ ligands.

DFT calculations (see $\mathrm{SI}$ for details) were performed at the BP86-D3/Def2-TZVP level on the simplified model $\mathrm{Ag}_{10}\left\{\mathrm{~S}_{2} \mathrm{P}(\mathrm{OMe})_{2}\right\}_{8}\left(\mathbf{1}^{\prime}\right)$. Its optimized geometry, characterized as an energy minimum, matches quite well with the $\mathrm{X}$-ray structure of 1 (Table S2), with a overestimation by $\sim 3 \%$ of the $\mathrm{Ag}-\mathrm{Ag}$ contacts, as expected at this level of theory. Its Kohn-Sham orbital diagram (Figure 4) exhibits a substantial energy gap of $1.85 \mathrm{eV}$. The HOMO lies $0.38 \mathrm{eV}$ above the HOMO-1. It can be identified as the $1 \mathrm{~S}$ superatomic orbital, with significant ligand admixture. It has a $35 \%$ contribution from the trigonal bypyramid (with almost equal participation of the five atoms). The four $\mathrm{Ag}_{\text {cap }}$ participate to a total of $18 \%$, whereas that of $\mathrm{Ag}_{\mathrm{ext}}$ is only $2 \%$. The three lowest vacant MOs can be viewed as the split $1 \mathrm{P}$ shell and their ligand contribution is modest. The averaged metal natural atomic orbital (NAO) charges range $0.32\left(\mathrm{Ag}_{\mathrm{tbp}-\mathrm{eq}}\right), 0.62\left(\mathrm{Ag}_{\mathrm{tbp}-\mathrm{ax}}\right), 0.68\left(\mathrm{Ag}_{\mathrm{cap}}\right)$ and $0.76\left(\mathrm{Ag}_{\mathrm{ext}}\right)$. The Wiberg bond indices (Table S5) indicate significant $A g_{\text {tbp-eq }}-A g_{\text {tbp-eq }}$ bonding, whereas the $A g_{\text {cap }}$ and $A g_{\text {ext }}$ atoms are mainly involved in metallophillic-like interactions. Taken all together, these results suggest that the two superatomic electrons are mainly localized on the trigonal bipyramid and mainly on its equatorial triangle. The TD-DFT-simulated UV-vis spectrum of $\mathbf{1}^{\prime}$ is shown in Figure $3 \mathrm{~b}$. It reproduces nicely the experimental spectrum. The band at $509 \mathrm{~nm}$ corresponds to a HOMO (1S) $\rightarrow$ LUMO (1 $\left.\mathrm{P}_{\mathrm{x}}\right)$ transition and that at 385 is mainly of HOMO (1S) $\rightarrow$ LUMO+1 $\left(1 \mathrm{P}_{\mathrm{z}}\right)$ character. The band of higher energy is split into two components (338 and $314 \mathrm{~nm}$ ), which are a mixture of the HOMO (1S) $\rightarrow$ LUMO+2 (1Py) and various ligand $\rightarrow$ metal transitions. An estimated $\mathrm{S} 1 \rightarrow \mathrm{S} 0$ emission wavelength, calculated by TD-DFT yielded a value of $688 \mathrm{~nm}$, corresponding to a $1 \mathrm{P}_{\mathrm{x}} \rightarrow 1 \mathrm{~S}$ transition. 
In conclusion, a new methodology is developed to prepare superatomic nanoclusters in a controllable fashion. $\mathrm{Ag}_{7}(\mathrm{H})\left\{\mathrm{S}_{2} \mathrm{P}\left(\mathrm{O}^{\prime} \mathrm{Pr}\right)_{2}\right\}_{6}$ in solution proceeds self-redox reactions to yield $\mathrm{H}_{2}$ and a new 2-electron silver superatom, $\mathrm{Ag}_{10}\left\{\mathrm{~S}_{2} \mathrm{P}\left(\mathrm{O}^{\prime} \mathrm{Pr}\right)_{2}\right\}_{8}$ of unique trigonal bipyramidal core structure. The transformation is triggered by visible light in slow speed or boosted by heating. Both $\mathrm{Ag}_{7}(\mathrm{H})$ and $\mathrm{Ag}_{10}$ cores have a similar trigonal bipyramidalbased skeleton, indicating that $\mathrm{Ag}_{7}(\mathrm{H})\left\{\mathrm{S}_{2} \mathrm{P}\left(\mathrm{O}^{\prime} \mathrm{Pr}\right)_{2}\right\}_{6}$ plays dual roles: a reducing agent and a template for cluster growth. $\mathrm{Ag}_{10}\left\{\mathrm{~S}_{2} \mathrm{P}\left(\mathrm{O}^{\prime} \mathrm{Pr}\right)_{2}\right\}_{8}$ exhibits strong red emission at ambient temperature in solution with quantum yield of $6.0 \%$. We hope this work, which uses a hydrido silver(I) cluster without adding extra reducing agents, can provide a new concept for synthesizing superatomic NCs. This work also provides a solid experimental proof that a hydrido silver(I) complex is a key component for the growth of superatoms even though they have been proposed in several occasions. ${ }^{[16]}$ It is anticipated those structurally characterized group 11 hydride clusters, ${ }^{[17]}$ if thermally stable, may eventually reach the stage of higher electron-count superatoms by applying this methodology.

\section{Acknowledgements}

This work was supported by the Ministry of Science and Technology of Taiwan (MOST 109-2113-M-259-008, 108-2923M-259-001), and the France-Taiwan ANR-MOST program (project Nanoalloys). The GENCI (Grand Equipment National de Calcul Intensif) is acknowledged for HPC resources (Project A0050807367).

\section{Conflict of interest}

The authors declare no conflict of interest.

Keywords: superatom $\bullet$ silver nanocluster $\cdot$ redox $\bullet$ silver $•$ hydride

[1] a) S. Maity, D. Bain, A. Patra, Nanoscale 2019, 11, 22685-22723; b) Y. Du, H. Sheng, D. Astruc, M. Zhu, Chem. Rev. 2020, 120, 526-622; c) X Kang, M. Zhu, Chem. Soc. Rev. 2019, 48, 2422-2457; d) R. Jin, C. Zeng, M. Zhou, Y. Chen, Chem. Rev. 2016, 116, 10346-10413.

[2] a) M. Walter, J. Akola, O. Lopez-Acevedo, P. D. Jadzinsky, G. Calero, C. J. Ackerson, R. L. Whetten, H. Grönbeck, H. Häkkinen, Proc. Natl. Acad Sci. U.S.A. 2008, 105, 9157-9162; b) H. Häkkinen, Chem. Soc. Rev. 2008, 37, 1847-1859.

[3] a) R. S. Dhayal, J.-H. Liao, Y.-C. Liu, M.-H. Chiang, S. Kahlal, J.-Y. Saillard, C. W. Liu, Angew. Chem. Int. Ed. 2015, 54, 3702-3706; Angew. Chem. 2015, 127, 3773-3777; b) L. G. AbdulHalim, M. S. Bootharaju, Q. Tang, S. D. Gobbo, R. G. AbdulHalim, M. Eddaoudi, D.-e. Jiang, O. M. Bakr, J. Am. Chem. Soc. 2015, 137, 11970-11975; c) C. P. Joshi, M. S Bootharaju, M. J. Alhilaly, O. M. Bakr, J. Am. Chem. Soc. 2015, 137 11578-11581; d) R. S. Dhayal, Y.-R. Lin, J.-H. Liao, Y.-J. Chen, Y.-C. Liu, M.-H. Chiang, S. Kahlal, J.-Y. Saillard, C. W. Liu, Chem. Eur. J. 2016, 22, 9943-9947; e) Z.-J. Guan, J.-L. Zeng, Z.-A. Nan, X.-K. Wan, Y.-M. Lin, Q.-M. Wang, Sci. Adv. 2016, 2, e1600323; f) W.-T. Chang, P.-Y. Lee, J.H. Liao, K. K. Chakrahari, S. Kahlal, Y.-C. Liu, M.-H. Chiang, J.-Y. Saillard, C. W. Liu, Angew. Chem. Int. Ed. 2017, 56, 10178-10182; Angew. Chem. 2017, 129, 10312-10316; g) X.-T. Shen, X.-L. Ma, Q.-L. Ni, M.-X. Ma, L.-C. Gui, C. Hou, R.-B. Hou, X.-J. Wang, Nanoscale 2017, 10, 515-519; h) X. Zou, S. Jin, W. Du, Y. Li, P. Li, S. Wang, M. Zhu,
Nanoscale 2017, 9, 16800-16805; i) Z.-J. Guan, F. Hu, S.-F. Yuan, Z.-A Nan, Y.-M. Lin, Q.-M. Wang, Chem. Sci. 2019, 10, 3360-3365; j) T. Omoda, S. Takano, T. Tsukuda, Small 2021, DOI: 10.1002/smll.202001439.

[4] H. Yang, J. Lei, B. Wu, Y. Wang, M. Zhou, A. Xia, L. Zheng, N. Zheng, Chem. Commun. 2013, 49, 300-302.

[5] Y. Kikukawa, Y. Kuroda, K. Suzuki, M. Hibino, K. Yamaguchi, N. Mizuno, Chem. Commun. 2013, 49, 376-378.

[6] H. Yang, Y. Wang, N. Zheng, Nanoscale 2013, 5, 2674-2677.

[7] a) Z.-Y. Wang, M.-Q. Wang, Y.-L. Li, P. Luo, T.-T. Jia, R.-W. Huang, S.Q. Zang, T. C. W. Mak, J. Am. Chem. Soc. 2018, 140, 1069-1076; b) Z. Wang, H.-F. Su, M. Kurmoo, C.-H. Tung, D. Sun, L.-S. Zheng, Nat. Commun. 2018, 9, 2094; c) Z. Wang, F.-L. Yang, Y. Yang, Q.-Y. Liu, D. Sun, Chem. Commun. 2019, 55, 10296-10299; d) Z. Wang, Q.-P. Qu, H.-F. Su, P. Huang, R. K. Gupta, Q.-Y. Liu, C.-H. Tung, D. Sun, L.-S. Zheng, Sci. China Chem. 2020, 63, 16-20; e) X.-M. Luo, C.-H. Gong, L. Zhang, S.-Q. Zang, Nano Res. 2020, DOI: 10.1007/s12274-020-3227-5.

[8] K. Yonesato, H. Ito, D. Yokogawa, K. Yamaguchi, K. Suzuki, Angew. Chem. Int. Ed. 2020, 59, 16361-16365; Angew. Chem. 2020, 132, 16503-16507.

[9] S.-F. Yuan, P. Li, Q. Tang, X.-K. Wan, Z.-A. Nan, D.-e. Jiang, Q.-M. Wang, Nanoscale 2017, 9, 11405-11409.

[10] K.-G. Liu, X.-M. Gao, T. Liu, M.-L. Hu, D.-e. Jiang, J. Am. Chem. Soc. 2020, 142, 16905-16909.

[11] C. W. Liu, Y.-R. Lin, C.-S. Fang, C. Latouche, S. Kahlal, J.-Y. Saillard, Inorg. Chem. 2013, 52, 2070-2077.

[12] C. W. Liu, J. T. Pitts, J. P. Fackler Jr., Polyhedron 1997, 16, 3899-3909

[13] K. K. Chakrahari, J. Liao, R. P. B. Silalahi, T.-H. Chiu, J.-H. Liao, X. Wang, S. Kahlal, J.-Y. Saillard, C. W. Liu, Small 2021, DOI: 10.1002/smll.202002544.

[14] CCDC 2054938 contains the supplementary crystallographic data for compound 1 in this paper. This data can be obtained free of charge from The Cambridge Crystallographic Data Centre via www.ccdc.cam.ac.uk/data_request/cif.

[15] I. Haiduc, L. Y. Goh, Coord. Chem. Rev. 2002, 224, 151-170.

[16] S, Sharma, K. K. Chakrahari, J.-Y. Saillard, C. W. Liu, Acc. Chem. Res. 2018, 51, 2475-2483.

[17] a) R. S. Dhayal, W. E. van Zyl, C. W. Liu, Acc. Chem. Res. 2016, 49, 86 95; b) T. Nakajima, K. Nakamae, Y. Ura, T. Tanase, Eur. J. Inorg. Chem. 2020, 2011-2226; c) C. Sun, B. K. Teo, C. Deng, J. Lin, G.-G. Luo, C.-H. Tung, D. Sun, Coord. Chem. Rev. 2021, 427, 213576. 
WILEY-VCH

\section{Entry for the Table of Contents}

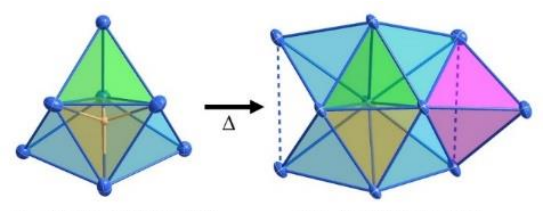

$\left[\mathrm{Ag}_{7}(\mathrm{H})\left\{\mathrm{S}_{2} \mathrm{P}(\mathrm{OR})_{2}\right\}_{6}\right](\mathrm{Oe})$

$\left[\mathrm{Ag}_{10}\left\{\mathrm{~S}_{2} \mathrm{P}(\mathrm{OR})_{2}\right\}_{8}\right](2 \mathrm{e})$

A self-redox reaction of $\mathrm{Ag}_{7}(\mathrm{H})\left\{\mathrm{S}_{2} \mathrm{P}\left(\mathrm{O}^{\prime} \mathrm{Pr}\right)_{2}\right\}_{6}$ leads to the formation of a highly emissive, two-electron $\mathrm{Ag}$ nanocluster, $\mathrm{Ag}{ }_{10}\left\{\mathrm{~S}_{2} \mathrm{P}\left(\mathrm{O}^{\prime} \mathrm{Pr}\right)_{2}\right\}_{8}$, without adding extra reducing agents. The metal framework of $\mathrm{Ag}_{7}$, a bicapped trigonal bipyramid, is highly correlated to that of $\mathrm{Ag}_{10}$, suggesting $\mathrm{Ag}_{7}(\mathrm{H})\left\{\mathrm{S}_{2} \mathrm{P}\left(\mathrm{O}^{\prime} \mathrm{Pr}\right)_{2}\right\}_{6}$ acts as both reducing agent and template in cluster growth. 